\title{
ARTIGOS
}

CIDADE, HISTÓRIA E CULTURA

\section{O PENSAMENTO MODERNO DE GASTON BARDET: LE NOUVEL URBANISME}

\author{
Virgínia Pontual* \\ Juliana Melo Pereira* \\ * Universidade Federal de Pernambuco, Programa de Pós-graduação em Desenvolvimento Urbano, Recife, \\ Pernambuco, Brasil.
}

\begin{abstract}
Resumo
O artigo apresenta o pensamento urbanístico de Gaston Bardet - urbanista francês do século XX - e está orientado pelo entendimento de que ele fez uma leitura crítica da cidade e das teorias então existentes, para formular uma ideia a devir. Partiu-se de uma inquietação: como Bardet construiu seu entendimento sobre o urbanismo moderno? Investigou-se o conjunto da obra de sua autoria, assim como a produção historiográfica sobre ele. A análise documental está pautada pela ordem dos textos, pelo modo como Bardet pronunciou, correlacionou, argumentou, realizou analogias, procedeu a reutilizações conceituais, em um dado contexto sociotemporal. Na primeira parte constam os enunciados sobre urbanismo construídos por Bardet, os quais permitem perceber as prioridades que ele considerava como desafios àquele recente campo disciplinar. Já a segunda é dedicada à formulação da utopia na obra Le Nouvel Urbanisme, que via o urbanismo não só como uma ciência, mas principalmente como uma disciplina dotada de forte caráter social.
\end{abstract}

Palavras-chave

Gaston Bardet; Urbanismo moderno; Enunciados; Le Nouvel Urbanisme; Dimensão social; Utopia. 


\title{
ARTICLES
}

CITY, HISTORY AND CULTURE

\section{THE MODERN THINKING OF GASTON BARDET: \\ LE NOUVEL URBANISME}

\author{
Virgínia Pontual* \\ Juliana Melo Pereira* \\ * Universidade Federal de Pernambuco, Programa de Pós-graduação em Desenvolvimento Urbano, Recife, \\ Pernambuco, Brazil.
}

\begin{abstract}
This article presents the urban thinking of Gaston Bardet - a twentieth century French urbanist - and is guided by the understanding of his critical reading of the city and of the current theories of the time, to formulate an idea of becoming. Its starting point was restlessness: was this the manner in which Bardet built his understanding of modern urbanism? His entire collection of work has been investigated, as well as his historiographical production. The documentary analysis was based on the order of the texts, the way in which Bardet pronounced, correlated, argued, analogized, and proceeded towards conceptual reuses, in a given socio-temporal context. The first part includes statements constructed by Bardet on urbanism, which enable us to perceive the priorities he considered to be challenges to that recent field of discipline. The second part is dedicated to the formulation of utopia in Le Nouvel Urbanisme, which viewed urbanism not only as a science, but primarily as a discipline endowed with a strong social character.
\end{abstract}

Keywords

Gaston Bardet; Modern urbanism; Declarations; Le Nouvel Urbanisme; Social dimension; Utopia. 


\title{
O PENSAMENTO MODERNO DE GASTON BARDET: LE NOUVEL URBANISME
}

\author{
Virgínia Pontual \\ Juliana Melo Pereira
}

1. Introdução

A constituição do campo do urbanismo é um tema inesgotável e aberto a muitas contribuições. Nesse sentido, a reflexão apresentada a seguir tem como foco o pensamento urbanístico de Gaston Bardet (1907-1989) e está orientada pelo entendimento de que ele era um homem de seu tempo, que fez uma leitura crítica da cidade e de teorias então existentes com o propósito de formular uma ideia do devir. Como dizem Botelho e Schwarcz (2009, p. 13), ao empreender essa reflexão, está se dando "ao tempo o seu tempo".

Mas, afinal, o que instigou a pesquisa sobre Bardet? A existência de estudos historiográficos que o rotulam com adjetivos por vezes contraditórios, tais como "construtor de uma abordagem original", "humanista”, "opositor do urbanismo modernista”, "teórico do urbanismo francês”, "místico”, "não conformista”, “conservador”, "formador de urbanistas”, “continuador de Marcel Poëte”, “codificador” e "produtor de um pensamento autônomo".

Para Frey (1999; 2001), Bardet atuou como um urbanista que constituiu uma abordagem original sobre as aglomerações urbanas. Ele também o qualifica como um dos principais teóricos do urbanismo francês até 1950, por ter atrelado a análise do espaço urbano ao espaço social, associando o urbanismo aos aportes da História, da Geografia e da Sociologia.

Cohen (1978a) corrobora a opinião de Frey quanto à elaboração, por Bardet, de uma abordagem original. De início, Cohen atribui a esse urbanista o adjetivo 
"humanista" e sua interpretação permanece acentuadamente positiva nos seus artigos de 1978b e 1989. O autor enfatiza que as posições bardetianas sobre "industrialização e forma urbana ou rural são parte da cultura arquitetural” na França (COHEN, 1978a, p. 75).

Nos artigos seguintes, nota-se um deslocamento: os escritos de Cohen propiciam uma leitura que ilumina um caráter positivo, ao reportar-se a Bardet como "uma figura maior do urbanismo francês do século XX" (1996, p. 135), para em seguida enunciar que a tese de Bardet deixa "transparecer uma certa admiração pelo fascismo" (1996, p. 136).

No artigo publicado em 1997, esse enunciado é retomado, atestando que Bardet não se furta de lançar as primeiras críticas contra a ideia de "homem estandardizado” de Le Corbusier (1997, p. 9). Ademais, em certos momentos Cohen (1997) reduz a leitura de Bardet aos embates e polêmicas aos quais atribui o isolamento desse urbanista, sem deixar de remeter também ao fato de ele ter adotado uma postura mística nos últimos anos de vida. De fato, a filosofia cristã sempre esteve presente no pensamento urbanístico de Bardet, sobretudo nas concepções que o fizeram reagir à emergência de um urbanismo funcionalista, cada vez menos humano. É provável que o deslocamento interpretativo de Cohen se deva a sua adesão à arquitetura e urbanismo modernistas, principalmente aquele apregoado por Le Corbusier.

Bullock (2010) e Rigotti (2001) seguem a mesma leitura de Cohen presente em seu artigo publicado na revista Zodiac (1997), ao afirmarem que o descrédito de Bardet na França foi resultado de sua contraposição ao urbanismo modernista e de sua participação como urbanista no governo de Vichy.

Outra leitura é a propalada por Pascal Balmand (1985), para quem Bardet faz parte de uma geração de intelectuais franceses enunciados como "não conformistas”, marcados pela guerra e inconformados com os laços de solidariedade que se perdiam, ao passo que uma sociedade operadora de máquinas se tornava o paradigma.

Mesmo sem tratar diretamente da contribuição de Bardet, Gutiérrez (2007) e Almandoz (2008) mencionam a circulação das ideias de autoria dele na América do Sul. Sua passagem pela Argentina é mencionada por Rigotti (2001); no Brasil, foi Pontual $(2011 ; 2016)$ quem fez esse registro. Todos esses autores destacam a capacidade apresentada por Bardet de atrelar os métodos de pesquisa social ao urbanismo e a rede de relações profissionais tecida entre o francês e os sul-americanos.

Calabi (1997) considera Gaston Bardet um “continuador” do discurso urbanístico fundado por Marcel Poëte. Esse argumento é corroborado por Manzione (2006, p. 5), que, ao abordar as vertentes do urbanismo como ciência, definiu Poëte como 
um "iniciador" que lançou as bases teóricas e Bardet como um "codificador" que desenvolveu investigações metodológicas. Na contramão desses estudos, Pereira (2019) afirma que Bardet construiu um pensamento autônomo, marcado pela capacidade de observação, síntese e teorização dos fenômenos urbanos; sem diminuir a relevância de Poëte, a autora descortina uma série de filiações, como Vidal de La Blache, Patrick Geddes, Fréderic Le Play, Emmanuel Mounier, entre outros.

Neste artigo, considera-se que Gaston Bardet constituiu um pensamento urbanístico próprio, denso, de forte apelo social e humanista, orientado pelas questões próprias de seu tempo. Neste sentindo, evitou-se uma leitura que o restringisse ao lugar de "opositor”, "polêmico”, “continuador” ou "conservador”: Bardet é lido como um autor, seu urbanismo, como um discurso.

Assim, para adentrar a reflexão sobre o pensamento urbanístico de Bardet, levantam-se duas questões: 1. Que concepções sobre urbanismo contêm os escritos de Bardet? 2. Como ele as construiu? As respostas a essas indagações partem da suposição de que seus escritos não só se inserem no campo do urbanismo, como contêm a adjetivação de moderno, adquirindo assim uma proposição específica. Considera-se que os escritos estudados compõem um corpus de proposições, jogos de definições, de técnicas e de instrumentos, que, ao serem apropriados por terceiros, são reelaborados de múltiplas maneiras.

$\mathrm{O}$ intento perseguido foi revelar como Bardet construiu seu entendimento sobre o urbanismo moderno. Essa instigação fundamenta-se na abordagem da ordem dos textos, ${ }^{1}$ na vontade de saber como Bardet os pronunciou, os correlacionou a outros textos, argumentou, realizou analogias e procedeu a reutilizações conceituais em dado contexto sociotemporal. A aplicação dessa abordagem passou pela leitura de seus escritos, os quais, de acordo com Chartier (1990, p. 12), são compreendidos "como práticas concretas e como procedimentos de interpretação". Isso significa que requerem a apropriação de temas, noções e enunciados, assim como o deslocamento segundo a ordem a ser dada pelo leitor ou investigador.

Resta ainda enfatizar que o encadeamento dos temas, noções e enunciados aqui presentes não se verifica de igual modo nas obras consultadas. Nestas, eles estão por vezes diluídos e dispersos; em outros momentos, sistematizados. A dificuldade encontrada para a leitura e a construção desta narrativa recai no fato de que Bardet tinha como habitus ${ }^{2}$ de escrita a prolixidade e a reduzida objetividade.

\footnotetext{
1. Sobre essa abordagem, adotaram-se como referências Botelho e Schwarcz (2009), Chartier (1990) e Foucault (2000). FOUCAULT, M. A ordem do discurso. São Paulo: Loyola, 2000.

2. A convergência das noções de representação, em Chartier (1990), e de habitus, em Bourdieu (2004), é professada pelo próprio Chartier (1990, p. 13, 16 e 17). Essa aproximação indica uma perspectiva de construção da História com base na relação com outros campos do saber. BOURDIEU, P. O poder simbólico. Rio de Janeiro: Bertrand, 2004.
} 
Também é necessário esclarecer que os escritos tratados foram elaborados por Bardet em um momento no qual suas experiências estavam assentadas na Argélia e na Europa, pois ele só veio às Américas depois de 1948.

A investigação realizada partiu do conhecimento do conjunto da obra de Bardet - livros e artigos de periódicos - e da produção historiográfica existente sobre ele, com base na qual - tendo como norte as questões expostas anteriormente - foi estabelecido o recorte temporal dos anos de 1930 e 1940. Nesse período, Bardet escreveu as seguintes obras: Roma de Mussolini (1937), Problèmes d'Urbanisme (1941), Principes Inédits d'Enquêtes et d'Analyses Urbaines (1943), Pierre sur Pierre (1945), L'Urbanisme (1947), Le Nouvel Urbanisme (1948) e Mission de l'Urbanisme (1949). Entre as revistas francesas de arquitetura e urbanismo foram trabalhadas aquelas que receberam mais publicações da autoria de Bardet, a saber L'Architecture Française (18); L'Architecture d'Aujourd'hui (12); Économie et Humanisme (12); La Revue d'administration communale (10), bem como aquelas de cujo corpo editorial ele fez parte: Urbanisme, Le Monde souterrain, Paris et la région capitale.

\section{Os enunciados sobre urbanismo elaborados por Bardet}

Gaston Bardet fez parte da segunda geração de urbanistas franceses. A primeira foi marcada pela atuação do Musée Social, dos conselhos de urbanismo e de Marcel Poëte e resultou na articulação do pioneiro Institut d'Urbanisme de l'Université de Paris (IUUP). ${ }^{3}$ Poëte também foi diretor da primeira revista francesa de urbanismo, intitulada La Vie urbaine, vinculada ao IUUP e reuniu artigos de Alfred Agache, Pierre Clerger, Adolphe Dervaux, Henri Prost e Henri Sellier sobre os temas prioritários: habitação social, cidades-jardim, reconstrução, além dos planos de organização promovidos com a aprovação da Loi Cornudet. ${ }^{4}$

Para Calabi (1997, p. 8, 71 e 77), Poëte foi o fundador do urbanismo como disciplina e buscou com afinco conferir unidade à história fragmentada das ideias e das transformações urbanas. ${ }^{5}$ Segundo a autora, a teoria vitalista bergsoniana foi

3. Em 1924, o curso de Urbanismo passou a integrar o Institut d'Urbanisme de l'Université de Paris (IUUP). Sobre o processo de reconhecimento universitário desse instituto, ver Chevalier (2000) e Lamas (2004). CHEVALIER, G. L'Entrée de l'urbanisme à l'Université. La création de l'Institut d'Urbanisme (19211924). Genèses, [s.l.], v. 39, n. 1, p. 98-120, 2000. Persee Program. doi: 10.3406/genes.2000.1624. LAMAS, J. M. Morfologia urbana e desenho da cidade. Lisboa: Calouste Gulbenkian, 2004.

4. Essa foi a primeira lei francesa de urbanismo, aprovada em 1919, objetivando determinar que as grandes cidades, as destruídas na Segunda Guerra Mundial, as de interesse histórico e as de vocação turística ou termal deveriam ser dotadas de planos reguladores de embelezamento e expansão.

5. Marcel Poëte estabeleceu as bases da disciplina na França. Em 1919, junto ao arquiteto Henri Sellier, ele atuou na criação da École de Hautes Études Urbaines (instituição que deu origem ao IUUP) e pela aprovação da Loi Cornudet. Ver Calabi (1997). 
adotada por Poëte no combate à ideia de que a cidade é redutível a uma matéria inanimada, a um simples aglomerado de edifícios construídos. Por sua vez, Poëte teria conferido a Bergson a inovação de um conceito que teria escapado aos geógrafos, o da "alma da cidade". Longe de ser considerado somente um disseminador das ideias de Poëte, veremos adiante que a filiação do pensamento urbanístico de Bardet é evidente, mas mesclada a outras importantes referências e guiada pelos desafios postos pela cidade do seu tempo.

Nesse contexto intelectual, Bardet concluiu sua formação em 1932 com a apresentação de sua tese no IUUP, publicada como livro, em 1937, sob o título Une Nouvelle ère romaine sous le signe du faisceau. La Rome de Mussolini ${ }^{6}$. Nessa obra, ele explicita os fundamentos de suas ideias em torno do urbanismo como ciência de evolução das cidades. As referências principais para a construção da tese foram seu orientador Marcel Poëte, principalmente por meio das obras Introduction à l'Urbanisme e Cours à l'Institut d'Urbanisme, e o filósofo Henri Bergson (PÖETE, 200o). Cabe destacar que sua tese foi elaborada sem que Bardet tivesse ido a Roma; ele utilizou a produção bibliográfica existente, principalmente francesa e italiana ${ }^{7}$. A primeira ida a essa capital ocorreu em 1935, quando participou do Congrès Internationale des Architectes, onde apresentou o artigo Paris, le centre d'échanges et les autoroutes souterraines, publicado posteriormente (BARDET, 1937b, p. 119).

La Rome de Mussolini é uma obra sobre como o urbanismo pode intervir na fisionomia e na "alma da cidade". Ainda que Cohen (1997) observe na escolha do tema o despontar do "conservadorismo" de Bardet, vale lembrar que a escolha do objeto de estudo não é surpreendente, se considerarmos que sua primeira formação foi na École National Supérieur de Beaux Arts. O interesse por Roma também é notável nos inúmeros artigos da revista Le Maître d'Euvre ${ }^{8}$, em especial em 1930, quando uma edição completamente dedicada à cidade foi organizada por Pierre Vago. Na apresentação, ele afirma que o desenvolvimento urbano de Roma, em diversas fases, era "um dos problemas mais interessantes do urbanismo moderno”, pois os remanescentes da cidade histórica constituíam um desafio para a elaboração de novos planos de organização e extensão. Vago conseguiu reunir e

6. A tese de Bardet defendida no IUUP, em 1932, intitulava-se La Rome de Mussolini, contribution à l'étude du plan régulateur 31. Posteriormente ele fez alguns acréscimos e a transformou em livro.

7. Entre as obras de língua italiana constam os relatórios dos planos citados e a obra homônima do arqueólogo Antônio Muñoz, La Roma di Mussolini, ao qual Bardet professou dever "informações valiosas" (BARDET, 1937, p. 107, tradução nossa).

8. Revista francesa de urbanismo fundada em 1926, pela l’Amicale de l’École spéciale d'architecture com a colaboração da Société des urbanistes diplômés do IUUP. Dirigida por Jean Royer, contou em seu corpo editorial com a participação dos urbanistas Marcel Poëte, Henri Sellier, Henri Prost e Alfred Agache. 
apresentar fontes oficiais (dados, gráficos, fotografias e cartografias) concedidas por engenheiros do escritório de organização da cidade de Roma, e a revista se tornou, portanto, uma preciosa fonte para a pesquisa de Bardet.

Logo, desde o primeiro trabalho, é notável que a busca de referências atuais e a conceituação do urbanismo foram um esforço constante de Bardet, presente na maioria de suas obras, quer como conceito principal ou secundário, quer apenas como pano de fundo. Cabe notar que essas noções não são estáticas; elas mudam, ganham outras nuances. Deve-se enfatizar que Bardet não as toma como excludentes; em vez disso, ele as mescla e as usa conforme fosse mais apropriado para o argumento em desenvolvimento.

Os recorrentes artigos na revista Urbanisme revelam o espaço de debate de Gaston Bardet e os principais temas discutidos relativos à compreensão dos fenômenos então presentes na cidade e na prática profissional dos urbanistas. Nessa revista, Bardet publicou seu primeiro artigo, "Naissance de l'Urbanisme" (1934). É perceptível o esforço em elaborar um conceito de urbanismo que associasse o entendimento bergonisiano de evolução, ao qual ele ainda estava preso, ao de utopia, referenciando-se em Saint-Simon, Charles Fourier e William Thompson, assim como ao de arte urbana, reportando-se a Napoleão III e a Haussmann, e à dimensão social norteada pelas ideias advindas principalmente do Museu Social. Esse esforço de formulação conceitual pode ser apreciado nas suas palavras: "A palavra urbanismo, uma síntese de ideologias bem francesas, é uma dupla afirmação: a afirmação de salvaguardar a vida da cidade como um ser organizado e a afirmação de salvaguardar a vida dos habitantes menos favorecidos" (BARDET, 1934, p. 232, tradução nossa).

Para Bardet, as cidades portavam negatividades e desordens social e urbanística. Somente uma disciplina moderna poderia ordená-la e mudar essa situação. Segundo ele, "o urbanismo é uma disciplina moderna nascida de novas necessidades decorrentes dos seguintes fenômenos principais: multiplicação acelerada de seres humanos na superfície do globo, hipercondensação de seus lares, desenvolvimento hiperbólico do maquinismo em todas as suas formas e, finalmente, afirmação do direito de cada um à distribuição igual de água pura, ar puro, sol [...]” (BARDET, 1934, p. 232, tradução nossa).

Bardet situava o urbanismo como uma ideologia eminentemente francesa, que deveria proteger a vida da cidade e de seus habitantes menos afortunados. Ele generaliza esse entendimento para além das ideias francesas e passa a considerá-lo uma disciplina moderna, mas com o norte voltado à salvaguarda da vida humana. 
Em Roma de Mussolini, Bardet formula novamente um de seus entendimentos sobre urbanismo, como o estudo sobre o processo de formação do passado e de organização futura, tanto na escala da cidade como na do território. Nas obras Problèmes d'Urbanisme - esta escrita no âmbito das experiências realizadas no Atelier Superieur d’Urbanisme Apliqué (ASUA) ${ }^{9}$ - e Pierre sur Pierre (1945), ele propala:

O urbanismo é um conjunto de disciplinas. O urbanismo é antes de mais nada uma Ciência que se apega ao conhecimento das coisas, estuda metodicamente os fatos, pesquisa as causas primeiras, para, depois de um rigoroso trabalho de análise, tentar, em sínteses sucessivas, determinar, se não leis, pelo menos princípios orientadores; Nessa base, pode-se montar uma Arte aplicada que passe à ação, à criação de novas sínteses, materializando, por meio de cheios e vazios, os volumes nos quais os grupos sociais são abrigados, mas a aplicação dessa arte, após a análise científica, requer dupla escolha: escolha de componentes urbanos para tratar, modificar, criar; escolha das aplicações possíveis. Essa dupla escolha, envolvendo a determinação dos valores humanos, é, na essência, uma Filosofia (BARDET, 1941, p. 7, tradução nossa).

Ou seja, o urbanismo supõe a compreensão do passado para pensar o futuro. E mais: é, além de uma disciplina moderna, um conjunto de disciplinas que requer não só a apropriação da ciência, como a articulação de disciplinas científicas e artísticas, conjugando-as com a apreensão do universo sensorial e filosófico para enfatizar a dimensão existencial do homem.

Enquanto seu entendimento sobre urbanismo ganhava novos contornos, Bardet seguiu enfatizando uma leitura pessimista da cidade e acrescentou outros aspectos aos já elencados. Na obra Problèmes d'Urbanisme, a metrópole é descrita como um lugar opressor ao homem e à vida social. Essa negatividade, segundo seu autor, era decorrente do intenso e acelerado crescimento demográfico, denominado "revolução demográfica", e da produção industrial, tendo em vista que ambos levam a uma urbanização sem controle.

Outra compreensão negativa de Bardet (1947, p. 20), presente na obra L'Urbanisme, resulta das demolições em Paris, por ele denominadas “haussmannização insensível”, fator que provocou grandes transformações na cidade em dissonância com as leis naturais da evolução. A abertura de avenidas largas, o isolamento dos

9. O ASUA foi criado por Bardet quando era professor assistente do IUUP, atendendo à solicitação de um grupo de alunos por exercícios práticos complementares ao ensino da instituição. Funcionou entre 1938 e 1939 (BARDET, 1941). 
monumentos no contexto urbano e as demolições eram considerados uma agressão ao "ser urbano" (BARDET, 1948, p. 1).

Bardet destaca ainda os problemas voltados à composição urbana que conformam uma cidade sem embelezamento, na medida em que não há harmonia entre os elementos naturais e os construídos, entre o tecido antigo e o moderno. Tais inferências foram inspiradas em Camillo Sitte (1992), ${ }^{10}$ principalmente por meio dos desenhos.

Ao entender o urbanismo como um conjunto de disciplinas, ele incorpora aportes de outras, como a geografia em Vidal de la Blache, o planejamento urbano em Patrick Geddes e a sociologia em Émile Durkheim. Bardet pretendia propor uma forma de observação sobre como o homem constitui a cidade, ou melhor, o conhecimento do ser vivo, do ser social e do espaço social. Considerou como método científico o emprego de procedimentos como levantamentos sistemáticos, representação gráfica e modo de argumentar. Esse método bardetiano consta na obra Principes inédits d'enquêtes et d'analyses urbaines (1943), com a indicação de que a observação sistemática dos fatos e da experiência conduzia a inferências ou conclusões. Estas constituem o substrato para a formulação de propostas de outra ordem e para uma hierarquia urbanística da cidade futura.

Entretanto, esse método ganhou maior expressividade com a formulação de um modo de representação espacial dos dados analíticos colhidos nas enquetes urbanas, a topografia social. Com essa ferramenta, era possível detectar as escalas já existentes e suas transformações; identificar e espacializar os nós urbanos comerciais, os polos de reunião, as localizações sociais e os acidentes topográficos. Além de criar perfis das famílias que compõem as cidades. A representação desses dados analíticos era feita com o estabelecimento de cores, símbolos e traços para cada um, registrados em um mapa que permitia a interpretação do conjunto.

Apesar de tantos entendimentos já terem sido urdidos, Bardet não se dava por satisfeito. Assim, na obra Pierre sur Pierre (1945), uma coletânea de artigos escritos entre 1934 e 1944, que não constitui uma unidade documental, ele procedeu a um balanço da prática do urbanismo antes da guerra, razão pela qual intitulou a introdução "Dez anos de combate". Nesse tempo, ele formulou um arcabouço doutrinal, propagou ideias, técnicas e instrumentos, contrapôs-se a outras, para constatar que tais contribuições contaram com pequena assimilação. Desolado,

10. Camilo Sitte (1843-1903), arquiteto e historiador da arte austríaco, foi um ferrenho crítico do urbanismo moderno, ao se contrapor às soluções urbanísticas e arquitetônicas monótonas, repetitivas e desproporcionais, e ao priorizar aquelas de caráter artístico. 
Bardet promulgou que o urbanismo não funcionava e a prática expressava-se pelos “fantoches do urbanismo" (BARDET, 1945, p. X, tradução nossa).

Um dos questionamentos foi consubstanciado no tema tratado mais extensivamente em Pierre sur Pierre: a circulação. Isso se deveu à leitura feita por Bardet sobre a expansão urbana, percebida como desenfreada e responsável por levar à extrapolação dos limites municipais. Desse modo, os deslocamentos de pessoas e de mercadorias, e, de igual forma, os meios de transporte, assumiam o estatuto de função vital. Ou seja, o bom funcionamento dos órgãos do ser vivo cidade dependia da existência de uma circulação eficiente dos diversos meios de transporte.

A atenção de Bardet a essa temática reporta-se a um período anterior. Em 1933, recém-formado, ele participou do Group d’Études du Centre Urbain Souterrain junto a profissionais e pesquisadores que discutiam o aproveitamento do subsolo como resposta aos problemas decorrentes da concentração populacional e da circulação de pedestres, automóveis, ônibus e metrô. O meio encontrado para enfrentar esses problemas foi a elaboração da ideia de separação dos fluxos, resguardando a superfície do solo para o deslocamento das pessoas e o subsolo para os meios de transporte. A referência dessa solução para a circulação urbana foi o urbanista francês Eugéne Hénard (1982)11, destacado por Bardet (1939) como um "precursor" pelo ineditismo de suas propostas.

Essas ideias foram sistematizadas em artigos $^{12}$ nos quais Bardet desenvolve a proposta de separação dos tipos, fluxos e velocidades de circulação. Para ele, além de propiciar uma ocupação do solo mais saudável para as pessoas, a separação das circulações poderia reduzir a destruição do edificado na superfície, consistindo, enfim, numa ideia embasada na perspectiva evolutiva das cidades. Essa proposta era um contraponto às soluções que eram apresentadas, como aquela proposta para a Ville Radieuse por Le Corbusier. Sua contraposição era assim demonstrada: "Entre a cidade escravizada pela máquina de Le Corbusier e a sonhada por Duhamel ou a Comissão da Paris Antiga, há lugar para uma grande cidade de trocas, composta de duas cidades sobrepostas: uma reservada a tudo o que é humano" (BARDET, 1935a, p. 173, tradução nossa). Os enunciados sobre urbanismo formulados por Bardet adquirem sentidos que se articulam e completam. Eles sofrem outras adequações e

\footnotetext{
11. O urbanista francês Eugène Hénard, na obra Études sur les transformations de Paris (1903), propôs a separação dos fluxos viários em níveis e apresentou um estudo comparativo entre a estrutura viária das cidades de Londres, Moscou, Berlim e a própria Paris.

12. "Paris, les autoroutes souterraines de grand trafic à grande profondeur" (BARDET, 1935C); "Paris et les autoroutes souterraines” (BARDET, 1935b); "Le Centre d'échanges et les autoroutes souterraines de grande profondeur” (BARDET, 1937b); “La Paris souterrain” (BARDET, 1937a); “L'Organisation de l'urbanisme souterrain” (BARDET, 1938).
} 
ganham densidade conceitual e de filiações naquilo que se pode denominar utopia bardeniana.

\section{A utopia urbanística de Bardet: Le Nouvel Urbanisme}

Le Nouvel Urbanisme sintetiza e apresenta os fundamentos do pensamento urbanístico de Bardet, até então dispersos em muitos artigos e livros. Essa obra foi iniciada durante o inverno de 1943, em plena Segunda Guerra Mundial, e publicada em 1948, logo após a Liberação, com a finalidade de recapitular as bases de suas ideias a partir das quais, segundo disse o próprio Bardet, ele lança uma “nova concepção”. Sua maneira de organizar a escrita de seus textos foi mantida nessa obra, isto é, com a leitura crítica da cidade e de algumas teorias vigentes seguida da formulação das ideias. Das críticas feitas, as mais repetidas foram: i) a de que o urbanismo então praticado na França se efetivava por meio do divórcio entre práticas superadas e uma cidade em constante transformação, ii) a de que a máquina era priorizada em detrimento do homem, iii) aos danos sociais da hiperconcentração demográfica.

Bardet, logo no início, faz referência a Marcel Poëte e a Pierre Vago ${ }^{13}$ para criticar Le Corbusier, seu desafeto principal e a quem considerava a "antítese de Poëte” (BARDET, 1948, p. 17). Na narrativa realizada para apresentar suas referências teóricas, Bardet afirma que a aproximação entre a Geografia Humana e a História resultou da associação dos fundamentos formulados por Poëte e Vidal de la Blache. São feitas igualmente referências ao urbanista escocês Patrick Geddes e a seu discípulo Patrick Abercrombie, dado que Bardet considerava o primeiro como o precursor do "urbanismo essencial" ou "urbanismo social".

Essa posição foi conferida não apenas a Geddes, mas abrangeu outros intelectuais, tanto da França como de outros países europeus, como se percebe na citação a seguir: "Observe todos os precursores de uma nova ordem: Play e Reclus na França, W. H. Richl na Alemanha, Kropotkin na Rússia, Grundtwig na Dinamarca, estabelecem as bases para o urbanismo social. Mas Geddes parece o mais completo e mais orientado para o urbanismo stricto sensu” (BARDET, 1948, p. 19, tradução nossa).

Esses quatro urbanistas já haviam sido mencionados por Bardet em outras obras, e sua permanência em Le Nouvel Urbanisme indica forte filiação às concepções por eles formuladas. Bardet, ao dissertar sobre o "urbanismo social"

13. Pierre Vago foi diretor da revista L'Architecture d'Aujourd'hui. A relação entre Bardet e ele foi cordial inicialmente, porém, no período de reconstrução pós-guerra, ocorreram trocas de farpas públicas, como revelam os artigos publicados no jornal Le Maitre d'oeuvre (1949). 
formulado por Geddes, enfatiza o cumprimento da necessidade de proceder à articulação entre cidade, região e campo. Desses três lugares o foco maior coube à dimensão regional, considerada por Bardet um tipo ideal, uma unidade geográfica, social e espacial ${ }^{14}$. Dito isso, depara-se com a questão: esse urbanismo social foi incorporado por Bardet ao propor um novo urbanismo?

Referências às ideias contidas em obras de urbanistas, geógrafos, filósofos e sociólogos, em diversos momentos dessa obra, são uma maneira de demonstrar erudição e conhecimento do que estava em voga. Entretanto, não há como deixar de inferir que foi em Patrick Geddes, Camillo Sitte, Eugène Henard e Ebenezer Howard que Bardet fundamentou parte substantiva de seu universo de referências urbanísticas.

Esse universo de referências e enunciados de Bardet sobre urbanismo não explicita a compreensão que é enfatizada em Le Nouvel Urbanisme: aquela que propala que o urbanismo deveria ser praticado visando ao homem. Essa perspectiva aparece em Tomás de Aquino, ao qual Bardet (1948, p. 44) atribui a "concepção unicista do homem”, como contraposição à sua leitura do desequilíbrio entre o corpo e o espírito, decorrente da primazia da máquina no mundo moderno e de sua intensa utilização.

A participação do urbanista no Movimento Economia e Humanismo contribuiu para que adotasse a filosofia tomista, não só quanto à concepção unicista do homem, como também no que diz respeito ao primado do bem comum. ${ }^{15}$ Bardet participou desse movimento mediante a publicação de artigos na Revue Économie et Humanisme e a integração ao grupo de especialistas em jornadas de estudo e trabalho.

Pode-se dizer hoje que o primado do bem comum é uma utopia, uma figura imaginária. A proposição utópica não foi algo banal para Bardet. Apoiando-se em Bergson - daí ter escrito que a falta de utopia era a interrupção do ciclo vitalista -, ele também alude com detalhes às ideias do jurista e estadista inglês Thomas More, contidas em sua obra Utopia ${ }^{16}$. Coincidência ou não, More era um entusiasta

\footnotetext{
14. Patrick Geddes foi o responsável pela formulação de diversos planos regionais, tendo passado por Paris em 1878. Segundo Bardet, nas memórias escritas para o prefácio do livro Introduction a l'Urbanisme, de Pöete (2000), é sugerido que este último e Geddes teriam se encontrado entre os anos de 1919 e 1920.

15. O quadro conceitual do tomismo estabelece o primado do bem comum e dos valores espirituais sobre os materiais. Sobre o primado do bem comum, ver Pozzoli (2001). Sobre a adoção do tomismo pelo Movimento Économie et Humanisme, ver Pelletier (1996). POZZOLI, L. Maritain e o Direito. São Paulo: Loyola, 2001.

16. O romance Utopia, publicado em 1516, versa sobre qual seria o melhor estado de uma república e descreve uma ilha chamada Utopia, onde haveria uma sociedade perfeita, idílica, imaginária e inexistente em oposição às cidades existentes. MORUS, T. Utopia. Rio de Janeiro: Ediouro, s.d.
} 
propagador da ética cristã, o que explica a adoção ferrenha de Bardet às fórmulas utópicas. Há ainda referências a outras utopias, como La Nouvelle Atlantide, imaginada por Francis Bacon, em 1627, e Le Nouveau Monde Industriel, criada por Charles Fourier, em 1829.

Bardet cita ainda como referência as comunidades de trabalho criadas por Marcel Barbu, em 1940, que consistiram numa experiência operária intitulada Boitiers de Montrees du Dauphiné (Boimondau). Barbu aproximou-se dos padres dominicanos franceses Louis-Joseph Lebret e Henri Deroches e lhes apresentou essa experiência, que tanto os encantou a ponto de eles a tomarem como referência para o Movimento Economia e Humanismo. A pedagogia comunitária exercitada nessa experiência foi a singularidade então recepcionada, ou seja: os integrantes da Boimondau organizavam encontros para a formação geral, literária, artística, musical e esportiva a fim de permitir o desabrochar de cada indivíduo e também da comunidade (PELLETIER, 1996) ${ }^{17}$.

Outra correlação que Bardet estabeleceu nessa obra foi entre as concepções de Howard e Robert Owen ${ }^{18}$. Ao proceder à leitura de Owen, o urbanista escreveu que "a grande cidade e sua economia são um mal, não somente para a classe operária, mas para a sociedade inteira” (BARDET, 1948, p. 70, tradução nossa) ${ }^{19}$. Assim, para se contrapor à cidade grande, Owen idealizou uma comunidade operária com as seguintes características: casas para as famílias dos operários, escola maternal, armazém para a venda de mercadorias a preços baixos e controle de bebidas alcoólicas, apropriadas e adequadas por Bardet para propor a Cidade Comunitária.

Porém, não só urbanistas ou reformistas sociais foram apropriados por Bardet na construção de seu pensamento urbanístico. O literato social Herbert George Wells foi outro autor cujas ideias foram assimiladas por Bardet na consolidação das bases de seu pensamento urbanístico ${ }^{20}$. Esse literato, cujo pendor para utopias

\footnotetext{
17. Entre os integrantes da Boimondau havia aqueles que se dedicavam às atividades de formação. Para estes, o exercício de tais atividades era feito mediante a abdicação dos proventos e do tempo livre.

18. Robert Owen (1771-1858) é considerado um reformista social, um dos fundadores do socialismo e do cooperativismo. Empreendeu uma experiência em uma fábrica, a New Lanark, que se tornou referência para a Grã-Bretanha e para diversos outros países. Ver Almeida (2010). ALMEIDA, O. M. de A. Utopias realizadas da New Lanark de Robert Owen à Vista Alegre de Pinto Basto. Porto: Universidade do Porto, 2010. Disponível em: <https://repositorio-aberto.up.pt/bitstream/10216/55238/2/TESEMESOLGAALMEIDA000124431.pdf $>$. Acesso em: 14 jun. 2019.

19. As obras de Owen que Bardet leu foram Essays on the Formation of the Human Character (1813) e $A$ New View of Society and Other Writings (1818).

20. Herbert George Wells (1866-1946), segundo Iachtechen (2011), é reconhecido como “crítico social, divulgador científico, jornalista, socialista militante, enciclopedista, eugenista, futurista, arauto do internacionalismo e do governo mundial, [...]”. Ao escrever seus romances, buscava embasamento científico para suas ficções.
} 
é inegável, rejeitava a ascendência da máquina sobre o homem. Tais elementos ideológicos são encontrados nas obras The Time Machine (1895) e Anticipations (1901), ambas citadas pelo urbanista francês:

Em Anticipations, ele [Huxley] considera a influência do progresso mecânico e científico na vida e no pensamento humanos [...]. Essa análise das Anticipations não foi inútil, pois aporta três ideias fundamentais: difusão geral, agrupamento voluntário, criação de comunidades novas e diversificadas. Esta última noção de variedade, de diferenciação, em conformidade com a evolução, é violentamente oposta à sociedade fixa, uma sociedade de insetos, que Aldous Huxley nos apresentará (BARDET, 1948, p. 76-77, tradução nossa).

Desde a obra Problèmes d'Urbanisme, Bardet evocava os efeitos negativos que a industrialização e a máquina provocavam nas cidades, tais como a hiperconcentração demográfica e de atividades, o culto ao progresso material, o afastamento do homem da dimensão espiritual, a estandardização, o assalariamento industrial, o desemprego, o pauperismo e o despovoamento do campo. Em Le Nouvel Urbanisme ele distinguiu a máquina - como um instrumento útil - do maquinismo, ou seja, um processo de generalização e dominância da dimensão econômica sobre a social e espiritual: "As máquinas reduziram parte do trabalho duro, mas aumentaram, no momento, o trabalho 'quantitativo'; por outro lado, degradaram o trabalho do homem integral e não especializado. [...] Desemprego, pauperismo, despovoamento do campo, ainda fazem parte do resgate devido à ruptura do equilíbrio entre produção e consumo" (BARDET, 1948, p. 85-86).

A sociedade de massa apavorava Bardet; em razão disso, ele rejeitou a concentração, a estandardização, a especialização, as mudanças nos laços familiares e a reorganização das relações de produção no campo e na cidade, que acreditava decorrentes do "liberalismo capitalista que supõe um crescimento suficiente grande para que as desigualdades acabem por se compensar!” (BARDET, 1948, p. 93, tradução nossa).

Em contraposição à sociedade de massa, ele propôs o estabelecimento de limites populacional e territorial como um dos pilares da organização urbanística e social que deveria redirecionar a vivência do homem na cidade para obter uma vivência citadina desprendida do "maquinismo libertador" (BARDET, 1948, p. 126). Essa ideia foi apropriada do filósofo Emmanuel Mounier ${ }^{21}$, do arquiteto Jacques

21. Emmanuel Mounier (1905-1950), filósofo francês, foi fundador da Revue Esprit e um dos pensadores dos movimentos franceses ligados à democracia cristã. O personalismo como teoria estava afinado com o comunitário e contra o capitalismo. Ver Rampazzo (2014). RAMPAZZO, L. O personalismo de Mounier: uma inspiração para a Bioética? Revista Centro Universitário São Camilo, 8(3):330-341, 2014. Disponível em: <http://www.saocamilo-sp.br/pdf/bioethikos/155564/A07.pdf>. Acesso em: 15 jun. 2019. 
Lafitte $^{22}$ e do economista Marcel Malcor ${ }^{23}$. Segundo Bardet, o "maquinismo libertador" deveria assegurar um mínimo vital ao homem e ganharia expressão - na organização urbanística e social implantada de acordo com os estágios sucessivos, extensivos à cidade e ao campo, à produção industrial e à produção agrícola.

Outro pilar da concepção bardeniana da organização urbanística e social foi a compreensão de que esta deveria obedecer a uma ordem política e moral. Ao desenvolver o argumento da dimensão moral da política como base para a construção do edifício social, Bardet se baseia em diversos autores, alguns já citados, outros novos, como Charles Péguy e o dominicano Antonin-Gilbert Sertillanges este último era conhecido por articular sua filosofia moralista às vertentes tomista e bergsoniana. Esse entrelaçamento de apropriações evolucionistas e tomistas com forte vinculação aos movimentos e intelectuais cristãos constituiu uma das principais referências do substrato filosófico de Bardet.

Não se pode deixar de registrar o acento moralista e ideológico dos artigos constantes em Le Nouvel Urbanisme; Bardet estava simplesmente refletindo sobre e respondendo à agenda posta pela modernização e pelo liberalismo econômico presente na sociedade e no ambiente intelectual francês ${ }^{24}$. Contrapunham-se a esse liberalismo os movimentos da democracia cristã, entre os quais se incluía o Movimento Economia e Humanismo.

Para Bardet, o liberalismo teria provocado os crescentes custos dos serviços municipais, do crescimento ilimitado da população e do território, conduzindo inexoravelmente, segundo suas palavras, à congestão, à decadência, ao parasitismo, a um tecido humano em degenerescência e, ainda, a uma flagrante desigualdade: “[...] a grande cidade faliu nos dois planos: econômico e humano [...] onde se encontram os maiores flagrantes de desigualdade em matéria de riqueza e de recursos” (BARDET, 1948, p. 110, tradução nossa).

O símbolo da falência da sociedade apelidada por Bardet de "civilização maquinista” foi a megalópole (BARDET, 1948, p. 92), descrita como uma cidade con-

\footnotetext{
22. O arquiteto Jacques Lafitte (1884-1966) tornou-se conhecido por suas contribuições para a ciência das máquinas, inspirada na evolução biológica, principalmente por meio de sua obra Réfletions sur la Science des Machines, publicada em 1932. Ver Le Roux (2009). LE ROUX, R. L'Impossible constitution d’une théorie générale des machines? Revue de Synthèse, Springer Verlag/Lavoisier, 130, n.1, p. 5-36, 2009.

23. O economista Marcel Malcor publicou a obra Au delà du Machinisme em 1937, na qual afirma que não renunciava ao aperfeiçoamento técnico e procurava no domínio da economia uma orientação pautada pela instauração da humanização das trocas. Ver Xavier (1938). XAVIER, L. Marcel Malcor, Au delà du machinisme (compte-rendu). Revue néo-scolastique de philosophie, v. 41, n. 1, p. 327, 1938.

24. O liberalismo econômico tem como principal idealizador o economista britânico Adam Smith. Ele formulou as seguintes ideias: a acumulação de riquezas decorrentes do trabalho livre, a livre concorrência - ou seja, o mercado - como seus mecanismos de regulação: a mão invisível e a lei da oferta e da procura. Ver Smith (1947). SMITH, A. Riqueza de la naciones. Barcelona: Bosch Casa Editorial, vol. I, II, III, 1947.
} 
dicionada pela máquina, homogeneamente geométrica, com blocos de tamanho idêntico, separados por ruas e avenidas de largura uniforme. Ele atribuiu esse enunciado a Lewis Mumford, na obra Culture of Cities, de 1938, e nos estudos desenvolvidos na New York Housing and Regional Planning Commission. Após essa digressão sobre megalópoles, Bardet escreve sobre sua concepção de cidade social em oposição à cidade uniforme: "No entanto, esperamos, nos interstícios da cidade esmagadora, que novos órgãos de cooperação social e espírito social se definam: o sindicato, a sociedade científica, a cooperativa de consumo, a biblioteca pública, meios pelos quais o regime capitalista e militar possa um dia tornar-se um regime comunitário” (BARDET, 1948, p. 98, tradução nossa).

Cabe lembrar que sua referência vivencial era representada pelas evidentes diferenças nas condições de vida entre a grande cidade e o campo na França. No lugar campo, para Bardet, ainda era possível encontrar uma maneira de produção agrícola baseada em relações que levavam o homem em consideração.

Wanderley (2018), em sua narrativa sobre o mundo rural francês, afirma a existência de uma sociedade camponesa estável, no século XIX, baseada no controle da terra, no trabalho de membros da família e nas formas tradicionais de cooperação. Era um mundo autossuficiente e organizado a partir de vilarejos. Mas o que eram os vilarejos? Bloch (1968) entende esse lugar nos seguintes termos:

Os diversos indivíduos ou as demais famílias que exploravam o mesmo solo e cujas casas eram construídas próximas umas das outras, no mesmo bairro rural ou no mesmo vilarejo, não viviam apenas lado a lado. Unidos por muitos laços econômicos e sentimentais, esses "vizinhos" [...] formavam uma pequena sociedade, a "comunidade rural", ancestral da maior parte dos municípios - ou sessões de municípios - de hoje [...]. No espaço, a comunidade rural se definia pelos limites de um território, sujeito a diversas regras de exploração comuns (regulamentação de cultura temporária, de pastagem nas terras comuns, datas das colheitas, etc.) e, sobretudo, a servidões coletivas em benefício do grupo de habitantes (BLOCH,1968, p. 172 e 173).

Vale enfatizar que a máquina foi inserida na produção agrícola lentamente, entre o final do século XVIII e o início do século XIX, pelos grandes proprietários de terra e facilitada pelo crescimento demográfico e pela elevação do preço da mão de obra. Foi por essa razão que os pequenos produtores rurais mantiveram durante um longo período as formas tradicionais de produção, o controle da terra e a organização territorial nos vilarejos.

Diante da disseminação das relações de produção capitalista na França, essa estrutura socioeconômica e territorial no campo manteve-se e propiciou o estabele- 
cimento de uma dicotomia com a cidade, com duas formas de organização opostas. Os estudos franceses sobre o mundo rural dão conta de que, na virada do século XX, iniciou-se a passagem da sociedade camponesa para a de agricultura familiar, ou seja, do camponês para o agricultor, conservando, entretanto, a forma da pequena produção mercantil. E mais: segundo Wanderley (2018, p. 69), o período entre 1914 e 1969 representa o processo de modernização da agricultura que introduziu uma produção agrícola mercantilizada, em que as duas formas sociais - a agricultura familiar (estabelecimento produtivo, família e vilarejo) e a produção industrial capitalista - coexistiram no campo.

O conhecimento da coexistência dessas duas formas sociais conduziu Bardet ao entendimento de que estava em curso a perda de uma maneira de vida social mais endógena, estável e permeada de traços familiares conservadores. Isso o levou à formulação, defesa e disseminação dessa organização de vida social por meio dos escalões comunitários.

O urbanismo realizado para o homem ganhou formato urbanístico quando Bardet propôs a "Cidade Humana ou Comunitária” (BARDET, 1948, p. 233). Essa cidade seria edificada tendo como referência a dimensão corporal ou a escala do homem, tanto para a ordem material como para a espiritual. Esse princípio construtivo, segundo Bardet, foi apropriado de Bergson, na obra Les Deux Sources de la morale et de la religion, publicada em 1932, e de François Perroux, na obra Pour un renouvellement de l'économie et de la sociologie moderne, de 1942. As palavras de Bardet consolidam o entendimento sobre a escala do homem: "Em vez de procurar obter as sociedades abertas por uma série de federações, sociedades estruturadas à medida do homem [...]. Todo mundo precisa de um quadro em sua escala, nem muito pequeno nem muito grande, e que possa valorizá-lo" (BARDET, 1948, p. 192, tradução nossa).

Porém, foi mediante sua participação nas jornadas e sessões de estudo do Movimento Economia e Humanismo que Bardet pôde consolidar a ideia sobre os princípios e elementos componentes da ordem comunitária. Dentre esses eventos, destacam-se: i) a sessão de estudos de Saint-Baume, com o tema Proprieté et Communauté; ii) a jornada de Mont-Dore, que consistiu em outro evento, no qual participaram duzentos franceses, de origem e formação diversas.

Durante esta jornada, aconteceu o grupo de trabalho intitulado L'Ordre communautaire. Dentre os trabalhos apresentados, estava o de Bardet, Installation des communautés sur le territoire ${ }^{25}$. Posteriormente, em 1944, ainda foi publicado o

25. Foram apresentados 22 trabalhos de vários autores, as conclusões do grupo L’Ordre communautaire, principes d'une économie humaine foram escritas por Lebret e J. M. Gatheron e publicadas na Revue Economie et Humanisme, n. 6, mar.-abr. 1943. Fond Lebret, AN 45 AS 45 e 47. 
livro Caractères de la communauté. Nesse livro constam artigos de Perroux, Bardet e outros integrantes do movimento, como Henri Desroche, Gustave Thibon e Louis Gardet. Com o aporte das contribuições citadas, Bardet formulou uma ideia filosófica sobre comunidade: “Com a comunidade, chegamos ao ápice do 'nós', porque ela realiza a fusão de consciências e atividades, a fusão de atividades conscientes, portanto, a consciência do bem comum” (BARDET, 1948, p. 202, tradução nossa).

Como essa definição poderia ser insuficiente, Bardet diferencia as organizações societária, cooperativista e comunitária, em função do fundamento funcional. A primeira estaria baseada no controle, a segunda se apoia no acordo e a terceira, no consenso interno. $O$ urbanista segue caracterizando uma organização comunitária como um ser orgânico e espontâneo, com funções e atividades hierarquizadas e que deveria ser replicada a fim de formar uma federação de comunidades.

A comunidade é um todo orgânico e espontâneo, uma obra de história e geografia. Hierarquiza funções complementares que despertam e expressam a fusão de atividades e consciências na ocasião de elementos comuns e de objetos comuns. [...] É por isso que o desabrochar total do homem deve ser feito na cidade, que é uma comunidade de comunidades. Federação orgânica de grupos [...] (BARDET, 1948, p. 203 e 204, tradução nossa).

Cada comunidade deveria ocupar um território delimitado e exercer funções específicas e complementares. Tais territórios foram por ele denominados "grupos de vizinhança” (BARDET, 1948, p. 209). Essas ideias podem ser encontradas na obra Pierre sur Pierre e foram retomadas em L'Urbanisme, mas foi em Le Nouvel Urbanisme que Bardet as desenvolveu detalhadamente e ao mesmo tempo lhes conferiu uma posição na estrutura textual que denota o sentido de síntese e expressão formal dos fundamentos adotados.

As comunidades, como deveriam apresentar especificidades e complementaridades funcionais, cobririam amplo espectro constitutivo, o que levou Bardet a prescrever uma classificação hierarquizada conforme o tamanho e as relações sociais que as marcariam. Assim, as comunidades, de acordo com o critério de compatibilização de funções e atividades com o espaço geográfico ou segundo uma ordem geoeconômica, foram classificadas em patriarcais, domésticas e paroquiais $^{26}$.

26. O primeiro escalão seria conformado por uma aldeia que congregasse entre 5 e 10 famílias; o segundo abrangeria uma povoação de 50 a 150 famílias, e o terceiro caracterizaria um bairro contendo de 500 a 1.500 famílias, considerando a distância que uma criança poderia percorrer a pé para ir de casa à escola. Ver Bardet (1948). 
O escalão patriarcal é o grupo elementar onde os vizinhos se ajudam mutuamente [...] é uma constante social aceitável. [...] O escalão doméstico é um bairro da cidade ou vilarejo, que se distingue de conjuntos de ruas e praças de vida própria [...] alimentando-se de um pequeno comércio múltiplo [...] o primeiro elemento realmente urbano [...] do qual a federação constituirá o escalão superior, conhecido anteriormente sob os nomes de bairro, subúrbio ou vilarejo. 0 escalão paroquial evoca o papel comunitário que a paróquia desempenhou alguns séculos atrás (BARDET, 1948, p. 216, 218, 220, 223 e 226, tradução nossa).

A federação de comunidades seria para Bardet a fusão dos escalões patriarcais, domésticos e paroquiais, que resultaria na "Cidade Comunitária”. Para ele, essa fusão formaria níveis superiores de organização geossocial ${ }^{27}$. Os escalões superiores já seriam uma degradação das relações sociais e comunitárias, daí ele definir uma escala urbana ótima da ordem de 5 mil a 15 mil famílias. Bardet ainda estabeleceu como diretrizes de controle a limitação do crescimento dos escalões; a criação no território das metrópoles de comunidades de 10 mil famílias, de maneira a garantir a permanência de um ambiente biologicamente salutar; e a implantação nacional de uma política de descentralização populacional e de atividades.

Esses escalões conformavam uma composição que Bardet enuncia no artigo “Nouvelle Démonstration: L’Organisation poliphonique” (1950), como um modo de ordenar os seres urbanos sem perder a variedade, tão prezada por seus referenciais Camilo Sitte, Raymond Unwin e Lewis Mumford.

Porém, o "novo urbanismo" de Bardet não se restringiu a unidades urbanas; ele propôs também um ordenamento que compreendia o campo, as regiões e o país por meio da noção de ordenamento espacial [aménagement de l'espace]. Essa noção, proveniente da geografia, após a Segunda Guerra Mundial, em face de uma França destruída e precisando ser rapidamente reerguida, passou a fazer parte da agenda intelectual do país. Bardet a enunciou primeiro em L'Urbanisme e depois, sem sofrer mudança de entendimento, em Le Nouvel Urbanisme. Nos anos 1950, ela recebe nova denominação, "ordenamento territorial”, principalmente com a promulgação do trabalho Pour un Plan d'aménagement du territoire', anunciado por Eugène Claudius-Petit, então ministro da Reconstrução e do Urbanismo.

Bardet participou desse debate e, antecipando-se à formulação governamental, propôs que esse ordenamento buscasse equilibrar a repartição da população

27. A fusão dos escalões resultaria em organizações socioespaciais assim denominadas por Bardet: metropolitana - com 50 mil a 150 mil famílias - e metropolitana capital - com 500 mil a 1.500.00o famílias. Ver Bardet (1948). 
ou as comunidades sobre o território, mediante a cooperação entre as diversas unidades geoeconômicas hierarquizadas territorialmente e a implantação de uma política de descentralização das cidades polos ante as unidades rurais, condensando e atualizando suas premissas de equilíbrio e hierarquia.

\section{Considerações finais}

Bardet construiu os enunciados ora fazendo uma leitura crítica do contexto citadino existente na França, especialmente em Paris, ora se contrapondo às ideias em voga no contexto intelectual europeu e estadunidense, ora fundamentando sua visão filosófica e doutrinária em múltiplos autores, entre os quais se podem destacar Poëte, Bergson, Blache, Aquino, More, Geddes, Sitte, Howard, Unwin, Owen, Wells e Mumford. Bardet refletiu sobre as diversas vertentes de pensamento que gravitavam ao seu redor, e as leituras distintas e às vezes divergentes que suscita mostram que esse urbanista pode estimular reflexões sobre o urbanismo contemporâneo.

Considerando o conjunto de autores referenciados e o diálogo que Bardet estabeleceu com eles, tanto por intermédio de vivências ou contatos pessoais como por meio de obras escritas, é inquestionável que ele foi um urbanista de seu tempo, um urbanista moderno. É empobrecedor restringir o urbanismo moderno a aqueles que labutaram em torno dos Congressos Internacionais de Arquitetura Moderna e que tiveram nas Américas uma recepção entusiástica, tornando-se uma concepção hegemônica. É preferível descortinar horizontes diversos, em que as diferenças ocupam espaços intelectuais pouco convergentes e consoantes.

Nos escritos de Bardet, são encontradas diversas concepções sobre urbanismo. Observou-se que elas não são excludentes, nem datadas, mas formuladas para dar respostas às questões apresentadas pelo campo. Assim, pode-se apreender o urbanismo como ciência de evolução das cidades, ideologia de salvaguarda da vida da cidade e dos homens menos favorecidos, disciplina moderna de previsão das necessidades humanas, conjunto de disciplinas relativas à ciência, arte, filosofia, topografia social e vias subterrâneas. O assento nos valores humanos é uma permanência, enquanto o adjetivo moderno emerge, em especial, por meio da tríade ciência, arte e filosofia, tornando-se, daí por diante, também, outra permanência.

A utopia formulada por Bardet na obra Le Nouvel Urbanisme via o urbanismo não só como uma ciência de evolução das cidades, mas principalmente como uma disciplina de forte caráter social. Essa ciência apresentava os seguintes requisitos: ser realizada para o homem, corpo e espírito, tendo como norte o primado do bem comum e a dimensão moral da política; assim, deveria assegurar o mínimo vital a todos os homens, mesmo que em estágios sucessivos. Bardet ainda prescreveu 
como princípios urbanísticos a adoção da ideia de cidade-jardim howardiana, o estabelecimento de um limite populacional e territorial e a articulação entre cidade, região e campo.

Porém, ressalta-se que o novo urbanismo de Bardet é distinto do urbanismo social geddeniano, em virtude não só de o francês ter adotado o princípio doutrinário de que as ideias e propostas urbanísticas deveriam ser realizadas para o homem, isto é, mediante o entrelaçamento de apropriações evolucionistas e tomistas, sem distinção entre corpo e espírito, como, ainda, por propor a utopia da cidade humana ou comunitária.

A conotação de que a prática e o pensamento de Bardet eram conservadores não pode ser confirmada, e sim problematizada. Não há dúvida de que ele admirou a modernização empreendida por Mussolini em Roma, de que fez um plano urbanístico para a cidade de Vichy no governo do marechal Pétain, de que se apoiou na moral cristã e na estrutura familiar patriarcal para argumentar contra as transformações que vivenciava. É certo que ele abominava o fenômeno da grande cidade e da disseminação da civilização maquinista, considerados emancipadores, naquele e no momento atual, por aqueles que advogam a cidade sem história. Ainda, sabemos que ele tinha grande empatia pelo mundo rural da agricultura familiar francesa.

Mas, por outro lado, Bardet criticou o liberalismo econômico, filiou-se a Tomás de Aquino, ao Movimento Economia e Humanismo, a Geddes, a Howard e a Owen para tornar inequívoca sua utopia da cidade humana ou comunitária. Diante desse universo de referências, interlocuções e filiações, não se pode propalar que, por discordar de Le Corbusier e da cidade funcional modernista, Bardet seja conservador. Trata-se de uma conclusão desqualificadora de suas contribuições à teorização do urbanismo que o mantém esquecido e isolado, especialmente, na França. Seriam todas as formulações desenvolvidas por ele e apresentadas ao longo deste texto, redutíveis a essa oposição?

A presente narrativa historiográfica mostra que Bardet elaborou um pensamento urbanístico próprio, no qual sobressai sua adesão a uma vertente orientada pelo apelo social e humanista. Essa vertente é parte da agenda do campo do urbanismo com base na qual é possível dialogar com autores como Paquot (2008) e Bourdieu (2012) - o primeiro por criticar a valoração das torres ou atuais cidades maquinistas como procedente dos superlucros auferidos pelos fundos de financiamentos, opondo-se assim a uma perspectiva social e humana; e o segundo por propagar que a atualidade rompe com os fundamentos da solidariedade e impõe a divisão social e a miséria em escala global. Tais referências geram uma indagação: a atualidade de Bardet nos levaria a vê-lo, ainda, como um pensador conservador? 
Não, pois sua utopia contempla dimensões manifestamente atuais: as sociais, as ambientais e as culturais.

\section{Referências}

Acervos e fontes documentais

SIAF/Cité de L'Architecture et du patrimoine/Archives d'architecture du XXe siècle, Fonds Bardet.

Centre des Archives Contemporaines, Fontainebleau, Fonds Lebret (AN 45).

Artigos de Gaston Bardet

BARDET, G. Naissance de l'urbanisme. Revue Urbanisme. Paris, Urbanisme, n. 28, p. 232-233, jui.-sep. 1934.

Qu'est-ce que l'urbanisme? Revue d'Administration Comunale. Paris, Federation Nationale du Personel de Services Publics, n. 48, p. 75-81, mar. 1935a.

Paris et les autoroutes souterraines. Revue Urbanisme. Paris, n. 35, p. 164-173, avr. 1935b.

Paris, les autoroutes souterraines de grand trafic à grande profondeur. Revue Travaux. Paris, Éditions Science et Industrie, p.157-162, avr. 1935c.

La Paris souterrain. Revue L'Architecture d'Aujourd'hui. Paris, n. 5-6, p. 39-41, jui. 1937a.

Le Centre d'échanges et les autoroutes souterraines de grande profondeur. Revue Le monde souterrain. Paris, G.E.R.C.U.S., n. spécial Activité au sous-sol, p. 83, jan. 1937 b.

L’Organisation de l'urbanisme souterrain. Revue OSB. Paris, OSB, n. 1-7, p. 191-201, juil. 1938.

Livros de Gaston Bardet

BARDET, G. La Roma de Mussolini: une nouvelle ère romaine sous le signe du Faisceau. Paris:

CH. Massin et C. Editeurs à Paris, 1937.

Problèmes d'urbanisme. Paris: Dunod, 1941.

. Principes inédits d'enquêtes et d'analyses urbaines. Paris: Colma, 1943.

. Pierre sur Pierre: construction du Nouvel Urbanisme. Paris: L.C.B. Editeurs, 1945.

. L’Urbanisme. Paris: Puf, 1947. (Que sais-je?).

. Le Nouvel Urbanisme. Paris: Vincent, Fréal et Cie, 1948.

. Mission de l'urbanisme. Paris : Les Éditions ouvrières, 1949. 
Fontes bibliográficas

ALMANDOZ, A. Entre libros de historia urbana: para una historia de la ciudad y el urbanismo en América Latina. Caracas: Editorial Equinoccio, 2008.

BALMAND, P. Piétons de Babel et de la cité radieuse: les jeunes intellectuels des années 1930 et la ville. Vingtième Siècle. Revue d'histoire. Paris: Centre National de Lettres, n. 8, octobre-décembre, 1985, p. 31-42.

BLOCH, M. Les caractères originaux de l'histoire rurale française. Tomo 1. Paris: Armand Colin, 1968.

BOTELHO, A.; SCHWARCZ, L. (org.). Um enigma chamado Brasil: 29 intérpretes e um país. São Paulo: Companhia das Letras, 2009.

BOURDIEU, P. (coord). A miséria do mundo. Petrópolis: Vozes, 2012.

BULLOCK, N. Gaston Bardet: post-war champion of the mainstream tradition of French urbanisme. Journal Planning Perspectives, [s.l.], v. 25, n. 3, p. 347-363, jul. 2010.

CALABI, D. Marcel Poëte et les Paris des années vingt: aux origines de l'histoire des villes. Paris-France/Montreal-Canadá: L’Harmattan, 1997.

CHARTIER, R. História cultural: entre práticas e representações. Rio de Janeiro: Bertrand Brasil AS/Difel, 1990.

CHOAY, F. O urbanismo. Utopias e realidades, uma antologia. São Paulo: Perspectiva, 2005.

COHEN, J.-L. Gaston Bardet: un humanisme à visage urbain. Revue Architecture, Mouvement, Continuité. Paris: Societé des architectes diplomés par le gouvernement, n. 44, 1978a.

. Entretien avec Gaston Bardet. Revue Architecture, Mouvement, Continuité. Paris: Societé des architectes diplomés par le gouvernement, n. 44, 1978b.

Ville sur ville, le destin de Gaston Bardet. Revue L'Architecture D'Aujourd'hui. Paris: L'Architecture d'Aujourd'hui, n. 265, oct. 1989.

Le 'nouvel urbanisme’ de Gastón Bardet. Revue Le Visiteur. Ville, territoire, paysage, architecture. Paris: S.F.A, n. 2, printemps 1996.

Gaston Bardet e la Rome de Mussolini. Revue Zodiac, n. 17, p. 70-85, mai. 1997.

FREY, J. P. Gaston Bardet: L'espace social d'une pensée urbanistique. Revue Les Études Sociales. Paris: Société d'économie et de science sociales, v. 130, p. 57-82, jul. 1999.

Gaston Bardet, théoricien de l'urbanisme 'culturaliste'. Revue Urbanisme. Paris: Urbanisme, n. 319, p. 32-36, Juil.-aoû. 2001.

. Généalogie du mot urbanisme. Revue Urbanisme. Paris: Urbanisme, n. 340, p. 63-71 jan. 2001a.

. Gaston Bardet, 1907-1989. In: PAQUOT, T. (org.). Les faiseur de villes. Espanha: Infolio, 2010.

GUTIÉRREZ, R. O princípio do urbanismo na Argentina. Parte 1 - 0 aporte francês, Arquitextos, São Paulo, a. 8, n. 087.01, Vitruvius, ago. 2007. Disponível em: http://www.vitruvius. com.br/revistas/read/arquitextos/08.087/216. Acesso em 24 jul.2014. 
HENÁRD, E. Les Transformations de Paris (8 fascicules): Paris: Libraries-Imprimieres Reúnies, 1903-1906. (republicação: Paris: L’Equerre, 1982).

IACHTECHEN, F. L. Evolução, progresso e universalidade: elementos do conceito de história em H. G. Wells. In: SIMPÓSIO NACIONAL DE HISTÓRIA, 26, 2011, São Paulo. Anais do XXVI Simpósio Nacional de História. São Paulo: Anpuh, 2011. Disponível em: http:// www.snh2011.anpuh.org/resources/anais/14/1300642689_ARQUIVO_textoANPUH2011-fabioiachtechen.pdf. Acesso em: 14 jun. 2019.

MANZIONE, L. Déclinaisons de l'“urbanisme comme science”. Discours et projets: Italie et France (1920-1940). Tese (Doutorado) - Université Paris 8. Paris, 2006.

Économie du lien et biopolitique. Gaston Bardet et l'urbanisme comme science sociale. Espaces et sociétés, n. 140-141, p. 193-213, 2010-1.

PAQUOT, T. La folie des hauteurs: pourquoi s'obstiner à construire des tours? Paris: Bourin Éditeur, 2008.

PEREIRA, J. Para florescer pessoas: o pensamento urbanístico de Gaston Bardet. Tese (Doutorado), UFPE/MDU. Recife, 2019.

PELLETIER, D. Economie et Humanisme: de l'utopie communautaire au combat pour le tiers-monde, 1941-1966. Paris: Les Éditions du Cerf, 1996.

POËTE, M. Introdution à l’urbanisme. Paris: Sens \& Tonka, 2000.

PONTUAL, V. O engenheiro Antônio Bezerra Baltar: prática urbanística, CEPUR e SAGMACS. Revista Brasileira de Estudos Urbanos e Regionais, [S.1.], v. 13, n. 1, p. 151, mai 2011. Disponível em: http://rbeur.anpur.org.br/rbeur/article/view/29o. Acesso em: 02 ago. 2014.

SAGMACS. O Urbanismo Aplicado do mestre Gaston Bardet: conferências, cursos e instituições. Urbana - Revista Eletrônica do Centro Interdisciplinar de Estudos da Cidade, v.8, p. 89-110, 2016.

RANDLE, P. Evolución urbanística: una teoría de la cuidad en la historia. Buenos Aires: Ed. Universitaria de Buenos Aires, 1972.

RIGOTTI, A. M. Un francés en las pampas. Los viajes a America de Gaston Bardet. Revista $A \& P$, Facultad de Arquitectura, Planeamiento y Diseño de la Universidad Nacional de Rosario, n. 15, p. 8-17, jul. 2001.

SITTE, C. A construção das cidades segundo seus princípios artísticos. São Paulo: Ática, 1992.

WANDERLEY, M. de N. B. Uma singularidade histórica: o olhar de uma pesquisadora brasileira sobre o mundo rural francês. Recife: Ed. UFPE, 2018. 


\section{Virgínia Pontual}

Professora do Programa de Pós-graduação em Desenvolvimento Urbano da Universidade Federal de Pernambuco (UFPE). Presidente da Anpur - Associação Nacional de Pós-graduação e Pesquisa em Planejamento Urbano e Regional, biênio 2013-2015. Líder do grupo pesquisa CNPq/UFPE: Laboratório de Urbanismo e Patrimônio Cultural (LUP, http://lup-ufpe.net.br/temp/). Pesquisadora da rede de pesquisa: Urbanismo no Brasil. Representante da área de Planejamento Urbano e Regional no CNPq (2015-2018). Bolsista produtividade 1 C do CNPq. Áreas de pesquisa: história do urbanismo, história da cidade, teoria do urbanismo, patrimônio cultural, planos urbanísticos.

Email: virginiapontual@gmail.com

ORCID: 0000-0001-8626-6675

Contribuição de autoria: conceituação; análise formal; obtenção de financiamento; metodologia; administração do projeto; supervisão/orientação; escrita - primeira redação.

\section{Juliana Melo Pereira}

Arquiteta e urbanista. Doutora pelo Programa de Pós-graduação em Desenvolvimento Urbano da Universidade Federal de Pernambuco (UFPE). Doutorado Sanduíche na l'École d'Urbanisme de Paris/Université Paris-Est Créteil Val-de-Marne (PDSE/Capes). Pesquisadora do Laboratório de Urbanismo e Patrimônio Cultural (LUP, http://lup-ufpe. net.br/temp/). Áreas de pesquisa: história do urbanismo, história da cidade, teoria do urbanismo, conservação e patrimônio cultural, legislação urbana, planos urbanísticos.

Email: melo.arquiteta@gmail.com

ORCID: 0000-0002-1277-9627

Contribuição de autoria: curadoria de dados; investigação/pesquisa; metodologia; validação; visualização; escrita - revisão e edição.

Submissão: 19 de julho de 2019.

Aprovação: 12 de abril de 2020.

Como citar: PONTUAL, V.; PEREIRA, J. M. O pensamento moderno de Gaston Bardet: Le Nouvel Urbanisme. Revista brasileira de estudos urbanos e regionais. v.22, E202011, 2020. DOI 10.22296/2317-1529.rbeur.202011

Artigo licenciado sob Licença Creative Commons CC BY-NC 4.0. https://creativecommons.org/licenses/by-nc/4.o/deed.pt_BR 